\title{
Research on the Path and Countermeasure of Intelligent Manufacturing Reform in Wuhan
}

\author{
$\mathrm{Yi} \mathrm{Gu}$ \\ Physical School \\ Jianghan University \\ Wuhan, China \\ 275939829@qq.com
}

\author{
Chenwei Zhao * \\ Business School \\ Jianghan University \\ Wuhan, China \\ 1755413061@qq.com
}

\begin{abstract}
The Internet, big data and other technologies have become the engine of the development of intelligent manufacturing industry, and intelligent manufacturing is showing a trend of modularization, open-source and individualization. At present, although China's smart manufacturing has made outstanding progress, there are still many development bottlenecks such as key parts and components being subject to people, high-end markets facing foreign investment, and insufficient attention to software systems. Based on the analysis of the current status of smart manufacturing development at home and abroad, this paper analyzed the current status, problems, advantages, and opportunities for intelligent manufacturing in Wuhan. Many corresponding countermeasures and suggestions were put forward to explore the suitable development path for the intelligent manufacturing industry in Wuhan. It provided a reference for the path and mode of intelligent manufacturing in other regions of China.
\end{abstract}

Keywords-Intelligent Countermeasures

manufacturing;

Wuhan;

\section{INTRODUCTION}

Manufacturing is the main pillar of the national economy, and it is also the main field of "innovation, transformation and upgrading" of China's economy in the future. China has become a big manufacturing country, but it is still not a manufacturing power. Creating a new advantage in China's manufacturing and realizing the transition from a big manufacturing country to a manufacturing power is the most important thing for China's economic development in the new era.

At present, industries in various countries are undergoing new technological revolution, and the global industrial technology system, development mode and competition pattern are facing great challenges. Developed countries have promulgated many "re-industrialization" national strategies, which focus on the advanced manufacturing industry. The United States vigorously promotes the construction of intelligent manufacturing system characterized by "industrial Internet" and "new generation robot"; German "industry 4.0" plans to improve the competitiveness of manufacturing industry through intelligent reform of manufacturing industry[1];Japan, South Korea and other manufacturing powers have also proposed corresponding strategic measures to develop smart manufacturing. China's "Made in China 2025" strategy launched in 2015 also emphasized the importance of intelligent manufacturing. Under the current industrial system characterized by high speed, excellent structure, new driving force and multiple challenges, intelligent manufacturing can not only promote the transformation and upgrading of China's industry but also reshape the competitive advantage of manufacturing.

It can be seen that the development of intelligent manufacturing has aroused widespread concern from all walks of life, but there are few studies on smart manufacturing in specific cities. Based on the analysis of the current status of domestic and foreign intelligent manufacturing, this paper used SWOT analysis method to analyze the current status, advantages, disadvantages, threats, and opportunities of intelligent manufacturing in Wuhan, in order to find a suitable path for Wuhan's intelligent manufacturing industry and provide reference for intelligent manufacturing reform in other parts of China.

\section{DOMESTIC AND FOREIGN INTELLIGENT MANUFACTURING INDUSTRY DEVELOPMENT STATUS}

\section{A. Foreign Intelligent Manufacturing Industry Development Status}

After the global economic crisis, many developed countries have implemented a series of national strategies to promote national economic growth and enhance the competitiveness of the real economy. Although the strategic plans are all different, they have a similarity: Emphasizing the importance of developing smart manufacturing.

\section{1) Intelligent manufacturing in the United States}

The US intelligent manufacturing industry is mainly to compensate for the cost disadvantage of the labor force. The US government has issued a series of policy documents, hoping to revitalize its manufacturing industry, hoping to lead a new round of technological revolution and reshape national competitive advantage. Since 2009, the United States has successively issued many documents, such as the "Revitalization of the US Manufacturing Framework", the "Manufacturing Promotion Act" and the "Advanced Manufacturing Partnership Program", aiming to reduce production costs and complete the technological revolution. In 2013, the United States formulated the "From the Internet to Robots - American Robot Roadmap" document that analyzes the roadmap of robots in various fields in the United States .It will promote the wide application of robot technology in 
various fields. It can be seen that the focus of the United States in the future smart manufacturing industry layout is the innovative robotic research. The popularity of industrial robots in the manufacturing industry will also greatly reduce the cost of labor in the United States.

\section{2) Intelligent manufacturing in Germany}

After the global financial crisis, the German economy recovered first, ahead of other developed countries in 2010. Two-thirds of its national economic growth came from manufacturing exports. Germany has always focused on the development of manufacturing, technological innovation and the management of complex production processes. In 2010, Germany published the "High-tech Strategy 2020", which will be the main project to cope with future global competition[1].

In Industry 4.0, the German Smart Factory will use social networks to interact with humans and nature based on the information physics system[2]. The intelligent factory will realize remote control and personalized production management. Germany will increase its investment in embedded manufacturing "smart production” systems, making production systems smarter[3].

\section{3) Intelligent manufacturing in Japan}

Japan's smart manufacturing started early. Since 1990, Japan has started research and experimentation in smart manufacturing. In 2015, the Japanese government published the "Robot New Strategy", intending to lead the "new era of robot." In addition, strict technical secrecy is an important feature of Japanese intelligent manufacturing. In order to ensure that core technology are not leaked and pirated, all large and medium-sized manufacturing companies generally set up corresponding intelligent manufacturing "R\&D Center", whose main function is to integrate the new technologies with the intelligent manufacturing equipment.

\section{B. Domestic Intelligent Manufacturing Industry}

In recent years, the Chinese government has implemented a series of strategic measures to promote the development and popularization of the intelligent manufacturing industries, in order to adapt to the development of Chinese industrialization and cope with the new round of industrial-technological revolution.

In 2015, the Chinese government regarded "Made in China 2025 ” as a national strategy, accelerated the integration of a new round of information technology revolution and manufacturing reform, promoted the intelligent reform of the manufacturing industry and reshaped the competitiveness of Chinese manufacturing[4]. Along with the publication and implementation of a series of policies and plans, the prospects for Chinese smart manufacturing are becoming clear, and the basic policy framework for promoting the development of intelligent manufacturing has been basically established.

Many governments in developed regions have already formulated intelligent manufacturing development plans to promote the local industrial revolution. Recently, major cities such as Shenzhen, Shanghai, Suzhou, Hangzhou, and Chengdu, published relevant policies on intelligent transformation.

In June this year, Shanghai issued the "Smart
Manufacturing Action Plan (2019-2021)”, which plans to build Shanghai into a key area for smart manufacturing applications and a core technology source by 2021. It will promote the coordinated development of the intelligent manufacturing industry in the Yangtze River Delta and the construction of two world-class intelligent manufacturing industry clusters for automobiles and electronic information.

Shenzhen has also issued relevant plans. It is planned that in the next three years, the total amount of technological transformation investment in the city will increase rapidly, the industrial quality will be improved significantly, and a clear quantitative target will be given. 100 digital workshops and intelligent factories will be built, and the number of new industrial robot applications will exceed 20,000.

It can be seen that from the country to the city,the industrial intelligent reform has become the main way to promote economic development.

\section{SWOT ANALYSIS OF INTELLIGENT MANUFACTURING INDUSTRY IN WUHAN}

\section{A. Advantages of Intelligent Manufacturing Industry in Wuhan}

In recent years, Wuhan intelligent manufacturing industry is growing rapidly, and its development advantages mainly include the following aspects.

\section{1) A good foundation of the intelligent manufacturing} industry

In recent years, Wuhan's “industrial multiplication” plan has been issued, and new industrial bases have emerged. Lenovo factories, General Motors Corporation, and Huaxing Optoelectronics have successively landed in Wuhan. In 2014, Wuhan advanced into "Trillion Club", and the city's comprehensive strength ranked in the top ten. From "industrial multiplication" to "intelligent transformation", Wuhan industry is taking a leap from quantity to quality, speed to efficiency. Nowadays, the integration of artificial intelligence technology, digital manufacturing technology and mobile Internet technology, as well as the development of related industries, have provided a good foundation for Wuhan intelligent manufacturing industry. In 2017, the sales volume of Wuhan photoelectronic enterprise exceeded 500 billion yuan, and Wuhan has become the largest photoelectronic industry cluster in the country. On April 26, 2018, the only national-level information photoelectronics innovation center in China was officially launched in Wuhan.

Wuhan attaches great importance to the development of the intelligent industry. At the beginning of this year, Wuhan took artificial intelligence as the main task of economic and social development in 2019, and also regarded the digital economy including artificial intelligence as one of the eight key industries for promoting high-quality development. Optics Valley has issued the first regional "Promoting Several Policies for the Development of Artificial Intelligence Industry”, which has initially formed an artificial industrial cluster centered on Xiaomi Technology and IFLYTEK CO., LTD. 


\section{2) Strong R\&D strength of intelligent manufacturing}

Wuhan is one of the most important science and education cities in China. Wuhan has 52 key universities with outstanding research capabilities, including Wuhan University and Huazhong University of Science and Technology, 106 scientific research institutions, 1 national laboratory (Wuhan National Laboratory for Optoelectronics), 1 major national scientific and technological infrastructure and 13 national key laboratories. Wuhan also has the first electronic information industry base in China(Optical Valley). Wuhan has rich intellectual and human resources, possessing 47 academicians from the Chinese Academy of Sciences and the Academy of Engineering. Liking optical communication (Huazhong University of science and technology), bioengineering technology(Huazhong Agricultural University and Wuhan University), laser technology(Huazhong University of science and technology), microelectronics technology (Wuhan University of Technology), pesticide science (Central China Normal University), geological and geological resources science, and new materials science(China University of Geosciences), their technological development strength is ahead of the other regions. The intelligent industry research and development system in Wuhan has been initially constructed.

\section{3) The location advantage of the intelligent manufacturing} industry in Wuhan

In recent years, with the implementation of the national strategy of "central rise" and "one belt and one way" in Wuhan, its strategic position in the overall situation keeps rising, and its location advantage is obvious.

Wuhan has always been known as the "thoroughfare of nine provinces". It is the largest water, land and air transport hub in China, the "heart" of China's economic geography. Wuhan plays a significant role in connecting the East and the west, the north and the south. Wuhan is becoming one of the four major railway transport hubs in China, where five main railway lines, namely Beijing Guangzhou Railway Line, Beijing-Kowloon High-speed Railway Line, Hankou Danjiangkou Railway Line, Shanghai Wuhan Chengdu Railway Line and Beijing HongKong Railway Line, and six national highways, including Beijing Zhuhai and Luzhou Chengdu, meet here. Water transport has formed a dense passenger and freight network, connecting the rivers and seas. Wuhan Port is an important port playing the role of connecting the four sides and opening to the outside world. Wuhan Tianhe Airport, the largest airport in Central China, is the only entry and exit port in Central China that can apply for visas on arrival. It is the four major hub airports in China. The huge transportation advantages promote the rapid development of the modern logistics industry in Wuhan.

\section{B. Disadvantages of Intelligent Manufacturing Industry in Wuhan}

Compared with the developed areas in China, Wuhan's intelligent manufacturing industry is relatively low. There are mainly the following deficiencies:

\section{1) Industrial innovation capability}

The technical level of Wuhan manufacturing needs to be improved. Except for steel, shipbuilding and laser manufacturing, other industries, such as software manufacturing and electronic communication, have gaps with other developed regions. Enterprises are real technology transformers, but the enterprises in Wuhan are lack of talents, innovation ability and technological resources. These are all the reasons for the limited development of Wuhan's intelligent manufacturing industry.

\section{2) Industrial brand status}

In history, the Yangge TV sets and lotus washing machines made in Wuhan are famous all over the country. However, in the wave of history, these brands have lost their tracks. The old brands have not been able to continue, and emerging brands are difficult to cultivate. Most of the manufacturing products are still mainly assembled and sold by OEM, lacking the localized production capacity of core parts such as high-performance servo motors, precision reducers, and controllers. These enterprises rely heavily on the supply channels of parts in overseas supply chains and other domestic regions. In order to build an advanced manufacturing center in Central China and realize the development and expansion of the intelligent manufacturing industry, Wuhan has brand awareness, market recognition and market share advantage.

\section{3) Status of industrial cluster}

Wuhan does not form a real industrial cluster. The real meaning of industrial clusters is the integration of all aspects of knowledge, production and social networks. The technological innovation of Wuhan's manufacturing industry has just started, whose knowledge integration efficiency and the added value of products is low, so the complete knowledge network has not yet been formed[5]. Wuhan's specialized labor system has not been perfected, and the social credit system has not yet been fully established. Wuhan needs to further reforms in order to truly gain the advantages of the three network-based industrial clusters. Moreover, lacking motivation, Wuhan's traditional automobile manufacturing industry has not promoted the development of industrial clusters.

\section{Opportunities for Intelligent Manufacturing Reform in Wuhan}

\section{1) Wide application market}

At present, the automotive, electronics and electrical industries are still the main driving force for the growth of global industrial robot sales. Wuhan is a well-known automobile capital and automobile production base, gathering 7 auto companies and more than 500 auto parts manufacturers. In 2017, the production and sales of automobiles in Wuhan Economic Development Zone reached 1.2 million, and the total industrial output value of the automobile and auto parts industry reached 258.74 billion yuan. The rapid development of Wuhan's automobile and electronics industries also provides a huge market demand for its intelligent reform.

2) Introduction of intelligent technology projects

With the implementation of many intelligent manufacturing policies and projects, Wuhan's smart manufacturing advantages are gradually emerging.

Since 2019, the government has issued three policies to promote the intelligent transformation of enterprises. The maximum reward for individual enterprise can reach 22 million 
yuan, and the intensity of intelligent transformation is unprecedented. It can be called the "first industry policy" for the current Wuhan manufacturing reform. Wuhan launched the intelligent transformation plan in April this year, and successively issued several policies, such as "The Work Plan for Promoting the Construction of Consulting and Diagnosis Platform ", "the Opinions on further stimulating the vitality of private investment and promoting the sustainable and healthy development of economy", and “Three year (2019-2021) action plan for the cultivation of high tech enterprises in Wuhan". In the policy text, it is found that the scope of "intelligent transformation" is broader, including industrial robots and digital workshops. Specifically, the policy text covers the improvement of the company's software and hardware, and the intelligent promotion in all parts of the production process, liking research and development, production management, logistics and after-sales.

In the past six months, the nation's smart manufacturing well-known service providers have been moving in Wuhan, such as Lenovo, Gechuang Dongzhi Technology Co., Ltd, Shanghai Mingjiang Intelligent System Co., Ltd. These well-known national enterprises quickly gathered in Wuhan, with a total investment of more than 1 billion yuan. At the same time, a large number of intelligent manufacturing talents gathered in Wuhan, and the intelligent manufacturing industry chain has gained an important part.

\section{Threats of Intelligent Manufacturing Reform in Wuhan}

1) The advanced technology of foreign intelligent manufacturing industry

Foreign intelligent manufacturing is ahead of China, and with the development of the global economy, manufacturing countries such as the United States, Japan and Europe have begun to focus on the Chinese market, especially the industrial robot market. At present, the foreign intelligent industry is fully deployed in China, and the market share has reached $70 \%$. However, at present, the core technology of key components in China has not been fully obtained. The development space of Chinese enterprises is limited.

2) Competitive domestic intelligent manufacturing market

At present, every region pays attention to the development of smart manufacturing. In order to seize its development opportunities, almost every province and city has established high-tech industrial parks, regarding the intelligent manufacturing industry as a key development target. For example, Shanghai issued the "Smart Manufacturing Action Plan (2019-2021)", which plans to build Shanghai into a key area for smart manufacturing applications and a core technology source by 2021. Wuhu, Anhui has issued many policies on the development of high-tech industry clusters, providing loans to key projects of high-tech intelligent production enterprises.

Countermeasures and Suggestions for Intelligent Reform of Manufacturing Industry in Wuhan

\section{Providing More Policy Support}

A series of related policies issued at the national and local levels have provided a good guide for the intelligent reform of manufacturing in Wuhan, but it is still necessary to further complete the policy support system and implement relevant policies effectively.

The government can set up special funds for the development of intelligent manufacturing industry to support the development of leading enterprises and the construction of major projects. It would be profitable to give priority support to these building projects of innovation and industrialization.

The government could give local enterprises some fiscal subsidies to purchase smart manufacturing. It can select typical enterprises in the Wuhan as experiments, such as automotive vehicles, parts and machinery, etc., to carry out comprehensive renovation and upgrading, and gradually promote them in the same industry. Wuhan should continue to promote the construction of intelligent equipment industrial parks and intelligent manufacturing towns and give full play to the role of industrial agglomeration (cluster).

It is also crucial to strengthen the construction of systems and standards, improve relevant laws and regulations, and provide more import and export support policies.

\section{E. Strengthening the Research of Core Technology}

It is essential to realize the intelligent reform and enhance the technological innovation capability and core competitiveness of Wuhan enterprises. Focusing on the market and industrial development needs, Wuhan manufacturing needs to accelerate the technical research of key parts and advanced productions, breaking through the limitation of industrial technology.

It is critical to increasing investment in technology research. Based on the technological requirements of automobile industry, welding industry and electronic industry, the research needs to combine intelligent operation technology and new controller technology; Wuhan could establish a public standardized and modularized service platform for intelligent manufacturing to share technology, which would benefit for promoting the industrialization process of mature intelligent products and enhancing the brand effect of industrial intelligent manufacturing in Wuhan; It would be profitable that the government establish a high-level industrial-technological $\mathrm{R} \& \mathrm{D}$ and testing platform, and increase investment to support the key technology research of industrial core components; The government also can establish industrial quality testing centers, setting smart manufacturing industry standards and encouraging performance testing and product certification for various industries.

Schools and enterprises are encouraged to train talents jointly, which is positive to promote technological innovation. Wuhan could make full use of its advantages in science and education resources, promoting school-enterprise cooperation, effectively integrating the advantages of production, learning, and research. In order to promote scientific and technological innovation, increase the quality of productions, Wuhan needs to make the innovative elements better integrated, and realize the optimal allocation of regional innovative technology resources in a larger scope[6]. 


\section{F. Actively Promoting the Development of Intelligent Manufacturing Industry}

Wuhan should seize the opportunity and give full play to their own advantages, give priority to the development of intelligent industries, lead the development of the industry from the application side. Moreover, in view of market changes and undecided development opportunities, the Wuhan manufacturing industry should make full use of the current technological innovations. With the comparative advantages of advanced technology and market scale, we should comprehensively play the advantages of the policy system, expand and strengthen the local intelligent robotics industry.

Wuhan manufacturing industry should make full use of opportunities, accelerate the layout and the new application of artificial intelligence technology, and finally take the leading position. At the same time, it should focus on the future direction of industrial competition and develop our own competitive advantages instead of competing with foreign advanced products with our own weaknesses.

Wuhan should actively confront challenges, carry forward its advantages, adhere to the principle of equality and mutual benefit when cooperating with others, and improve the level of self-innovation ability. Moreover, Wuhan manufacturing industry should take advantage of market demand and capital scale, actively cooperate with leading foreign companies. It is crucial to improve its industrial capabilities rapidly, accelerate the process of "China's creation", and build strong competitive domestic brands.

\section{G. Actively Promoting the Development of Characteristic Intelligent Productions}

In today's increasingly fierce regional competition, only by building our own characteristic brand, producing characteristic products and developing characteristic industry can we survive in the market competition. Based on the advantages of science and education, traditional manufacturing industry and huge market demand, Wuhan intelligent manufacturing industry needs to emphasize the word "characteristic" and concentrate all resources to develop characteristic manufacturing industries such as automobiles and electronics. Wuhan enterprises should focus on the future development trend, seek breakthroughs and occupy the market.

\section{H. Strengthening the Cultivation of Talents}

When cultivating talents, Wuhan should establish a new model combining study, research and practice and achieve joint training of talents in schools and enterprises.

Wuhan should strengthen the talent cultivation of the intelligent manufacturing industry, establish a library of scientific research talents in this field, promote the joint training of talents by universities, scientific research institutions, and intelligent manufacturing enterprises. It is significant to establish an incentive mechanism for industrial technology talents, and optimize the environment for talent growth. Wuhan manufacturing should cultivate a group of high-level leaders of scientific research and engineering applications. It can provide solid intellectual support for the development of Wuhan's intelligent manufacturing industry.
Wuhan can provide a good environment and quality services for related enterprises and talents through institutional innovation and management innovation to prevent the outflow of research and development results, production technology and talents.

\section{Actively Cooperation with Others}

Wuhan intelligent manufacturing industry should make full use of its regional advantages, market, scientific research and talent advantages. Based on the domestic market, the Wuhan manufacturing industry can carry out various forms of cooperation with advanced enterprises investing in Wuhan. On the one hand, Wuhan manufacturing can cooperate with relevant enterprises in developed countries such as Japan, Germany, the United States, and South Korea. On the other hand, cooperating with the advanced areas of the domestic intelligent manufacturing industry also can improve the level of intelligent manufacturing innovation in Wuhan. Wuhan manufacturing industry should find new ways to open to the outside world and encourage all advanced intelligent enterprises to set up research institutions in Wuhan to support the development of the intelligent manufacturing industry. This is conducive to Wuhan's international operation, participation in international cooperation and integration into the global industrial chain.

\section{SUMMARY}

Based on an in-depth analysis of the development status, problems, advantages and opportunities of Wuhan's manufacturing industry, we can get the conclusion that accelerating the intelligent reform of the Wuhan manufacturing industry should start from three aspects: government, enterprises and universities. There are six main measures: providing more policy support; strengthening the research of core technology; actively promoting the development of intelligent manufacturing industry; promoting the development of characteristic intelligent production; emphasizing the cultivation of talents; encouraging open cooperation.

\section{ACKNOWLEDGMENTS}

Foundation: WZ2018Y12, 2018 open fund of Manufacturing Industry Development Research Center on Wuhan City Circle, Jianghan University-Research on the Countermeasures of Transformation and Upgrading of Wuhan Manufacturing Industry under the Background of Intelligent Manufacturing.

\section{REFERENCES}

[1] S.Zhang, The Industry 4. 0 and Intelligent Manufacturing[J], Mechanical Design and Manufacturing Engineering, 2014, 43(08):1-5. (In Chinese)

[2] R.Zhong, H.Xu, E. Klotz, S.T.Newman, Intelligent Manufacturing in the Context of Industry 4.0: A Review[J], Engineering, 2017, 3(05):96-127. (In Chinese)

[3] J.Fu, Development status and trend of intelligent manufacturing equipment[J], Journal of Mechanical \& Electrical Engineering, 2014, 31(08):959-962. (In Chinese)

[4] J.Zhou, Intelligent Manufacturing-Main Direction of"Made in China 2025”[J].China Mechanical Engineering, 2015, 26(17): 2273-2284. (In Chinese) 
[5] T.Zhang, Research on Development Strategy of Wuhan Manufacturing[D], Wuhan University of Technology, 2009. (In Chinese)

[6] Yuliang Yin, Peizhen Li. Course Reform of Mechanical Manufacturing
Technology Foundation Based on Internet $+[$ P]. Proceedings of the 2019 International Conference on Management, Education Technology and Economics (ICMETE 2019), 2019. 